\title{
Effects of a total dietary fish oil replacement with vegetable oils to the survival, growth and development of the blue swimming crab portunus pelagicus early juveniles
}

\begin{abstract}
The feasibility of different vegetable based lipids as a complete replacement to dietary fish oil (FO) to blue swimmer crab Portunus pelagicus juveniles was assessed. A total of five iso-nitrogenous and iso-lipidic diets were formulated to contain FO, soybean oil (SBO), linseed oil (LSO), canola oil (CO), or palm oil (PO) as the main lipid source. The diets were fed to first staged juvenile crabs (total of 45 replicate crabs/treatment) over at least four molts. After 35 days, final sizes and weights were determined, and then measured for wholebody cholesterol. Crabs fed the FO, SBO, LSO, or CO-based diets showed similar specific growth rates $(\mathrm{SGR})(\mathrm{p}>0.05)$ for carapace length and width, which was significantly higher $(\mathrm{p}<0.05)$ compared to crabs in the dietary PO treatment. Whole-body cholesterol content was significantly lower for crabs fed the PO-based diets, which may have contributed to their poorer performance, compared to those fed the FO, LSO or CO-based diets. Results indicate $\mathrm{SBO}$, LSO or CO can totally replace FO, which may improve cost-effective and sustainable diets for portunid crabs. Further research into the use of dietary PO blends with other vegetable oils should be conducted.
\end{abstract}

Keywords: Fatty acid, Lipid replacement, Cholesterol, Portunids
Volume 5 Issue I - 2017

\author{
Nicholas Romano,' Shoyaib Kohinoor,' \\ Mahdi Ebrahimi, ${ }^{2}$ Nurul Amin SM,' Aziz \\ Arshad' \\ 'Department of Aquaculture, Universiti Putra Malaysia, Malaysia \\ ${ }^{2}$ Department of Veterinary Preclinical Sciences, Universiti Putra \\ Malaysia, Malaysia
}

Correspondence: Nicholas Romano, Department of Aquaculture, Faculty of Agriculture, Universiti Putra Malaysia, Malaysia,Email romano.nicholas5@gmail.com

Received: November 01, 2016 | Published: January 09, 2017

\section{Introduction}

The rising cost and unsustainable practice of utilizing wild caught marine oil sources have led to increasing research on suitable alternatives in the diets for both farmed fish and crustaceans. ${ }^{1}$ This is believed to be an important research direction for many sectors of the aquaculture industry to expand. Typically, vegetable oils are the focus of such research and among these, soybean oil (SBO) is perhaps the most investigated as a partial or complete replacement with relatively good results for various crustacean species. ${ }^{1,2}$

Crabs from the genus Eriocheir, Scylla and Portunus are being farmed in commercial ponds and their combined aquaculture production was over a million tonnes in $2014 .^{3}$ The farming of the blue swimmer crab Portunus pelagicus, however, is largely in the developmental stage despite a high market demand for this species with fisheries landings increasing from around 76,000 tones in 1990 to 180,000 tones in $2012 .{ }^{3}$ In general, the farming of portunid crabs is still heavily reliant on pellets designed for shrimp or are fed trash fish since feed formulations for these crabs are largely underdeveloped. ${ }^{4,5}$ Recently, however, there has been increasing research in this area. ${ }^{2,5,7}$

When various dietary fish oil (FO) to SBO ratios were compared, the sole inclusion of SBO led to lower survival and growth of $P$. pelagicus early juveniles while the best FO to SBO ratio was $1: 1 .^{2}$ It was suggested that this was due to the dietary provision of both $n-3$ and $\mathrm{n}-6$ fatty acids that likely reflected the natural feeding habits of these crabs that consist of both plant and animal material. ${ }^{2}$ Similarly, the use of dietary corn oil, which has relatively high levels of n-6 fatty acids, in a 1:2 ratio to FO was optimal for the survival and growth of mud crab Scylla serrata juveniles. ${ }^{8}$ Meanwhile, a corn oil and FO ratio of 1:1 also led to optimal survival of the mud crab $S$. serrata megalopae to the first crab stage while both the sizes and weights of the crabs were similar to those fed only FO as the lipid source. ${ }^{9}$ It has been suggested that optimal productivity can be achieved by balanced fatty acids, but is often specific to each species. ${ }^{10}$ In particular, the n-3 to $n-6$ fatty acid ratio has been demonstrated to greatly influence the growth of other shrimps, including the kuruma shrimp Marsupenaues japonicas ${ }_{11}^{11}$ white-leg shrimp Litopenaeus vannamei,${ }^{12,13}$ and black tiger shrimp Penaeus monodon. ${ }^{14}$

The feasibility of a total dietary FO replacement with vegetable sources to crustaceans has thus far been inconsistent. ${ }^{15-17}$ For $S$. serrata juveniles, the sole use of dietary SBO or sunflower seed oil caused significantly lower growth compared to crabs fed diets with only FO or in combination with sunflower seed oil and SBO after 65 days. ${ }^{17}$ On the other hand, Deering et al. ${ }^{15}$ found that $P$. monodon had significantly higher growth when fed diets containing canola oil (CO) or SBO compared to those fed lard or cod liver oil based diets. Similarly, when the giant freshwater prawn Macrobrachium rosenbergii were fed diets with FO, SBO, crude palm oil (CPO), $\mathrm{CO}$ or squid liver oil, growth was significantly better for prawns fed the CO-based diet compared to the FO or CPO-based diets..$^{18} \mathrm{Kim}$ et al..$^{18}$ noted that residual FO (from fishmeal) led to the presence of some long-chain polyunsaturated fatty acids (LC-PUFA) (of 5.9\%), which may have contributed to the relative success of using dietary vegetable oils. Indeed, dietary LC-PUFA deficiencies, due to the defattening of fishmeal and providing no FO, caused substantially lower survival and growth of $P$. pelagicus juveniles compared to when FO was added in relatively small amounts at $3 \%{ }^{19}$ or $1 \%^{2}$ On the other hand, when marine protein sources were absent in the diets of the Chinese mitten crab Eriocheir sinensis, growth was better for those fed SBO, rapeseed oil, coconut oil or beef tallow-based diets compared to crabs fed a FO-based diet. ${ }^{20}$ 
Currently, the feasibility of using different dietary lipid sources to $P$. pelagicus has not yet been investigated. The aim of this study was to feed $P$. pelagicus early juveniles with diets containing FO, $\mathrm{SBO}, \mathrm{CO}$, linseed oil (LSO) or palm oil (PO), and assess their survival, growth, development and whole-body cholesterol after 35 days.

\section{Materials and methods}

\section{Experimental diets}

A total of five iso-nitrogenous and iso-lipidic diets were formulated to contain different lipid sources that included fish oil (FO), soybean oil (SBO), canola oil (CO), linseed oil (LSO), or palm oil (PO) at $70 \mathrm{~g} / \mathrm{kg}$. The protein sources were fishmeal $(500 \mathrm{~g} / \mathrm{kg})$ and soybean meal $(100 \mathrm{~g} / \mathrm{kg})$, while phospholipid and cholesterol were supplemented at $60 \mathrm{~g} / \mathrm{kg}$ and $10 \mathrm{~g} / \mathrm{kg}$, respectively, to satisfy the requirements for portunid crabs. ${ }^{21,22}$ All sources of ingredients are provided as footnotes in Table 1. The diets were extruded according to ${ }^{23}$ and were kept in air-tight plastic bags at $-20^{\circ} \mathrm{C}$ for one month until use. The proximate composition of the diets was measured according to standard AOAC methods ${ }^{24}$ and was shown to be similar among the experimental diets.

Meanwhile, the fatty acid composition of the diets was measured according to. ${ }^{25}$ This was done by extracting the lipids using chrloroform:methanol $(2: 1 \mathrm{v} / \mathrm{v})$ and the fatty acid methyl esters (FAME) were prepared by transesterfication with $0.4 \mathrm{M} \mathrm{KOH}-m e t h a n o l$. This was followed by adding $14 \%$ methanolic boron trifluoride and then analyzed using a gas chromatograph (Aglient $7890 \mathrm{~A}$ ) using a $30 \mathrm{~m} \times 0.25$ $\mathrm{mm}$ ID $(0.20 \mu \mathrm{m}$ film thickness) Supelco SP-2330 capillary column (Supelco, Inc., Bellefonte, PA, USA). One microliter was injected by an auto sampler into the chromatograph, which was equipped with a split/split less injector and a FID detector. The injector temperature was set at $250^{\circ} \mathrm{C}$ while the detector temperature was $300^{\circ} \mathrm{C}$. The column temperature program initiated runs at $100^{\circ} \mathrm{C}$ for $2 \mathrm{~min}$., warmed to $170^{\circ} \mathrm{C}$ at $10^{\circ} \mathrm{C} / \mathrm{min}$, held for $2 \mathrm{~min}$, warmed again to $200^{\circ} \mathrm{C}$ at $7.5^{\circ} \mathrm{C} / \mathrm{min}$ and then held for $20 \mathrm{~min}$ to facilitate separation. Identification of fatty acids was done by comparing the relative FAME peak retention times of samples to standards obtained from Sigma (St. Louis, MO, USA), which are shown in Table 2.

The vegetable oil-based diets had much lower long-chain polyunsaturated fatty acids, which ranged from $9.88-11.30 \%$, compared to the FO-based diet of $30.96 \%$. The SBO-based diet had the highest amount of C18:2n-6, while the CO-based diet had the highest amount of C18:1n-9. Meanwhile, the dominant fatty acids in the LSO and PO-based diet were C18:3n-3 and C16:0, respectively.

Table I Ingredient formulation and proximate composition $\left(\mathrm{g} \mathrm{kg}^{-1}\right)$ of the experimental diets with different lipid sources

\begin{tabular}{llllll}
\hline & \multicolumn{7}{l}{ Experimental Diets } \\
& FO & SBO & CO & LSO & PO \\
\hline Fishmeal $^{\text {a }}$ & 500 & 500 & 500 & 500 & 500 \\
Soybean meal $^{\mathrm{b}}$ & 100 & 100 & 100 & 100 & 100 \\
Lecithin $^{\mathrm{c}}$ & 30 & 30 & 30 & 30 & 30 \\
Cholesterol $^{\mathrm{d}}$ & 10 & 10 & 10 & 10 & 10 \\
Vitamin premix $^{\mathrm{el}}$ & 40 & 40 & 40 & 40 & 40 \\
Mineral premix $^{\mathrm{e} 2}$ & 30 & 30 & 30 & 30 & 30 \\
Corn starch & 200 & 200 & 200 & 200 & 200 \\
Calcium phosphate $^{\mathrm{f}}$ & 10 & 10 & 10 & 10 & 10 \\
Choline chloride $^{\mathrm{g}}$ & 10 & 10 & 10 & 10 & 10 \\
Fish oil $^{\mathrm{h}}$ & 70 & & & & \\
Soybean oil $^{\mathrm{h}}$ & & 70 & & &
\end{tabular}

\begin{tabular}{llllll}
$\begin{array}{l}\text { Canola seed oil } \\
\text { Linseed oil }\end{array}$ & \multicolumn{3}{l}{70} & \\
$\begin{array}{l}\text { Palm oil } \\
\text { h }\end{array}$ & & & & 70 & \\
$\begin{array}{l}\text { Proximate Composition } \\
\text { Moisture }\end{array}$ & & & & 70 \\
Crude protein & 96.5 & 102.4 & 90.1 & 102.9 & 97.0 \\
Crude lipid & 423.0 & 411.3 & 419.3 & 415.8 & 414.5 \\
Crude ash & 137.6 & 131.8 & 147.6 & 143.2 & 140.7 \\
Crude fiber & 116.4 & 116.3 & 114.5 & 114.1 & 115.4 \\
\hline
\end{tabular}

aDanish fishmeal (moisture, crude protein, crude lipid, and crude ash of 89.7 , $694.6,72.1$, I $50.7 \mathrm{~g} \mathrm{~kg}^{-1}$, respectively, on as is basis)

bSoybean meal (moisture, crude protein, crude lipid, crude ash and crude fiber of 102.I, 462.8, $21.4,67.2$ and $50.5, \mathrm{~g} \mathrm{~kg}^{-1}$, respectively, on as is basis)

c30\% phosphatidylcholine (Sigma P364)

d92.5\% powder (Sigma C8503)

${ }^{\text {el,e2 }}$ same composition as Sukor et al. ${ }^{7}$

$f \geq 96.0 \%$ (Sigma 21218 )

g 98\% powder (Sigma C7527)

hfish oil (FO) from menhaden source (Sigma F8020) while soybean oil (SBO), canola seed oil (CO), linseed oil (LSO) and palm oil (PO) were all purchased from a local grocery store.

Table 2 Fatty acid composition (\% of total fatty acids) of the experimental diets with different oil sources

\begin{tabular}{llllll}
\hline \multicolumn{7}{c}{ Experimental diets } & & \\
& FO & SBO & CO & LSO & PO \\
\hline Individual fatty acids & & & & & \\
C14:0 & 3.54 & 4.52 & 2.13 & 3.62 & 4.47 \\
C16:0 & 16.43 & 17.98 & 11.54 & 12.32 & 34.32 \\
C16:In-7 & 4.69 & 6.72 & 2.76 & 2.88 & 2.67 \\
C18:0 & 6.38 & 5.34 & 4.85 & 1.13 & 6.39 \\
C18:In-9 & 14.73 & 14.47 & 39.63 & 11.16 & 21.14 \\
C18:2n-6 & 18.32 & 36.41 & 24.68 & 27.54 & 18.37 \\
C18:3n-3 & 4.95 & 3.26 & 4.41 & 31.47 & 2.50 \\
C20:4n-6 & 2.14 & 1.36 & 0.45 & 0.63 & 0.82 \\
C20:5n-3 & 8.85 & 3.54 & 3.39 & 3.65 & 3.68 \\
C22:5n-3 & 1.54 & 0.24 & 0.31 & 0.46 & 0.39 \\
C22:6n-3 & 18.43 & 6.16 & 5.85 & 5.14 & 5.25 \\
Major fatty acid groups & & & & & \\
$\Sigma$ SFA & 26.35 & 27.84 & 18.52 & 17.07 & 45.18 \\
$\Sigma$ MUFA & 19.42 & 20.19 & 41.39 & 13.04 & 22.81 \\
$\Sigma$ n-6 PUFA & 20.46 & 37.77 & 25.13 & 28.17 & 19.19 \\
$\Sigma$ n-3 PUFA & 33.77 & 14.20 & 14.96 & 41.72 & 12.82 \\
$\Sigma$ LC-PUFA & 30.96 & 11.30 & 10.00 & 9.88 & 10.14 \\
n-6/n-3 & 0.61 & 2.66 & 1.68 & 0.68 & 1.50 \\
\hline
\end{tabular}

SFA $=$ saturated fatty acid (sum of $\mathrm{Cl} 4: 0+\mathrm{Cl} 6: 0+\mathrm{Cl}$ 8:0)

MUFA = monounsaturated fatty acid (sum of $C 16: 1+C \mid 8: I n-9)$

PUFA = polyunsaturated fatty acid (sum of CI8:2n-6+CI8:3n-3)

LC-PUFA $=$ long chain polyunsaturated fatty acid (sum of C20:4n-6+C20:5n$3+C 22: 5 n-3+C 22: 6 n-3)$

$\Sigma \mathrm{n}-6$ PUFA $=($ sum of $\mathrm{CI} 8: 2 \mathrm{n}-6+\mathrm{C} 20: 4 \mathrm{n}-6)$

$\Sigma \mathrm{n}-3$ PUFA $=($ sum of $C 18: 3 n-3+C 20: 5 n-3+C 22: 5 n-3+C 22: 6 n-3)$

$\mathrm{FO}=$ fish oil; $\mathrm{SBO}=$ soybean oil; $\mathrm{CO}=$ canola oil $\mathrm{LSO}=$ linseed oil $\mathrm{PO}=$ palm oil. 


\section{Experimental design and set up}

The crabs were larvi cultured according to ${ }^{26}$ however, $1000 \mathrm{~L}$ plastic tanks were used instead of $300 \mathrm{~L}$. After the crabs settled to juveniles, which was within 12 hours of metamorphosis from the megalopae stage, they were siphoned out and a total of 225 intact and apparently healthy crabs were individually placed in $500 \mathrm{ml}$ clear plastic containers to prevent cannibalism. The crabs were then randomly assigned one of the five treatments and were immediately fed the experimental diets. This yielded 45 replicate crabs in each treatment and the culture units were located within a plastic lined room and an air heater maintained the temperature at $29 \pm 2^{\circ} \mathrm{C}$. The water was natural seawater, which was previously filtered (to $5 \mathrm{~mm}$ ) and ultraviolet sterilized.

The crabs were fed twice each day, once in the morning (9:00) and afternoon (15:00) and before feeding, any uneaten food was siphoned out, followed by a $20 \%$ water exchange. During this time, the presence of any morality or molts was recorded. If a mortality was found, their carapace length and width was measured using a digital caliper $(0.01 \mathrm{~mm}$; Mitutoyo, Japan). After one week, all the crabs were transferred to new containers, and the following week were all transferred to $5 \mathrm{~L}$ containers filled with $2 \mathrm{~L}$ of seawater. This was done to ensure hygienic conditions.

After 35 days, all the crabs were measured for their final carapace width and length as well as wet weights. The remaining crabs were kept at $-20^{\circ} \mathrm{C}$ to measure their whole-body cholesterol content within one month.

\section{Whole-body cholesterol}

From the remaining crabs, these were equally pooled in triplicate and their whole body was measured according to. ${ }^{23}$ Briefly, approximately 0.5 gram of sample was homogenized and then $3 \mathrm{ml}$ of $95 \%$ ethanol was added followed by $2 \mathrm{ml}$ of $50 \% \mathrm{KOH}$. After the samples were fully digested at $60^{\circ} \mathrm{C}$ for $10 \mathrm{~min}$., the solution was allowed to cool to room temperature and $5 \mathrm{ml}$ of hexane was added followed by $3 \mathrm{ml}$ of distilled water. Phase separation occurred after $15 \mathrm{~min}$ and the upper hexane layer $(2.5 \mathrm{ml})$ was removed and evaporated at $60^{\circ} \mathrm{C}$ under nitrogen gas flow. Then $4 \mathrm{ml}$ of o-phthaladehyde reagent was added followed by $2 \mathrm{ml}$ of concentrated sulfuric acid and then $6 \mathrm{ml}$ of distilled water. Absorbance was read at $550 \mathrm{~nm}$ and the results are expressed as mg 100g-1.

\section{Statistical analysis}

Data were checked for homogeneity and normality and were log-transformed if the assumptions were violated. Then, the data were subjected to a one-way ANOVA after prior confirmation of data homogeneity and normality, with the exception of the survival data. Survival was based on each crab acting as a replicate, which prevented variance. If significant differences were detected $(\mathrm{p}<0.05)$, a Duncan's post-hoc test was performed to identify differences among treatments. All statistical analysis was performed using SPSS (ver.22).

\section{Results}

\section{Survival, growth and development}

The survival ranged between $87.5 \%$ in the dietary SBO treatment to $62.5 \%$ in the dietary PO treatment (Table 3 ). The specific growth rates (SGR) for carapace width and length were significantly lower for crabs fed the PO-based diet, compare to all other treatments (Table 3). Except for crabs in the dietary CO treatment, those fed the PO-based diet had significantly lower SGR for wet weight than all others (Table $3)$.
Table 3 Survival and specific growth rate (SGR) (\% day-I) for carapace width, length and wet weights of the swimming crab Portunus pelagicus juveniles after 35 days of being fed diets with different lipids

\begin{tabular}{lllll}
\hline Treatments & $\begin{array}{l}\text { Survival } \\
(\%)\end{array}$ & $\begin{array}{l}\text { SGR } \\
\text { Carapace } \\
\text { width }\end{array}$ & $\begin{array}{l}\text { Carapace } \\
\text { length }\end{array}$ & Wet weight \\
\hline Fish oil & 77.8 & $3.68 \pm 0.09^{\mathrm{a}}$ & $2.66 \pm 0.08^{\mathrm{a}}$ & $10.37 \pm 0.25^{\mathrm{a}}$ \\
Soybean oil & 87.5 & $3.89 \pm 0.10^{\mathrm{a}}$ & $2.76 \pm 0.08^{\mathrm{a}}$ & $10.91 \pm 0.24^{\mathrm{a}}$ \\
Canola oil & 82.5 & $3.65 \pm 0.07^{\mathrm{a}}$ & $2.64 \pm 0.07^{\mathrm{a}}$ & $10.13 \pm 0.20^{\mathrm{ab}}$ \\
Linseed oil & 67.5 & $3.81 \pm 0.11^{\mathrm{a}}$ & $2.77 \pm 0.09^{\mathrm{a}}$ & $10.87 \pm 0.29^{\mathrm{a}}$ \\
Palm oil & 62.5 & $3.30 \pm 0.13^{\mathrm{b}}$ & $2.38 \pm 0.13^{\mathrm{b}}$ & $9.42 \pm 0.35^{\mathrm{b}}$ \\
\hline
\end{tabular}

SGR values are mean \pm SE, $n=27-36$. Different superscripted letters within each column are significantly different from each other (Duncan's multiple range test, $\mathrm{p}<0.05$ )

*no statistical tests could be performed due to each crab being a replicate.

For the first two molts (C1-C2 and $\mathrm{C} 2-\mathrm{C} 3)$, there was no significant difference in the intermolt duration (Table 4). By the third molt, however, crabs fed the SBO-based diet had significantly longer intermolt duration than crabs fed the FO, CO or LSO-based diets. Similarly, by the fourth molt, crabs fed the FO or LSO diets had significantly shorter intermolt durations compared to those fed the SBO or PO-based diets (Table 4).

Table 4 Molt interval (days) of the swimming crab Portunus pelagicus juveniles when fed diets with different lipid sources over four molts

\begin{tabular}{lllll} 
& Crab stage & & & \\
Treatment & CI - C2 & C2 - C3 & C3 - C4 & C4 - C5 \\
\hline Fish oil & $3.77 \pm 0.2^{\mathrm{a}}$ & $3.93 \pm 0.45^{\mathrm{a}}$ & $6.67 \pm 0.8 \mathrm{I}^{\mathrm{ab}}$ & $7.43 \pm 0.62^{\mathrm{a}}$ \\
Soybean oil & $3.55 \pm 0.23^{\mathrm{a}}$ & $4.48 \pm 0.43^{\mathrm{a}}$ & $8.00 \pm 0.94^{\mathrm{b}}$ & $11.00 \pm 1.07^{\mathrm{b}}$ \\
Canola oil & $3.73 \pm 0.17^{\mathrm{a}}$ & $3.36 \pm 0.39^{\mathrm{a}}$ & $5.47 \pm 0.53^{\mathrm{a}}$ & $7.93 \pm 0.69^{\mathrm{a}}$ \\
Linseed oil & $3.89 \pm 0.35^{\mathrm{a}}$ & $4.63 \pm 0.56^{\mathrm{a}}$ & $5.52 \pm 0.45^{\mathrm{a}}$ & $8.81 \pm 1.09^{\mathrm{ab}}$ \\
Palm oil & $3.64 \pm 0.15^{\mathrm{a}}$ & $4.84 \pm 0.58^{\mathrm{a}}$ & $7.76 \pm 0.98^{\mathrm{ab}}$ & $10.67 \pm 1.29^{\mathrm{b}}$ \\
\hline
\end{tabular}

Values are mean \pm SE. Different superscripted letters within each column are significantly different from each other (Duncan's multiple range test, $\mathrm{p}<0.05$ ).

Table 5 Whole-body cholesterol content (mg I00 g-I) of the blue swimmer crab Portunus pelagicus juveniles after 35 days of being fed diets with different lipids

\begin{tabular}{llllll}
\hline & $\begin{array}{l}\text { Fish } \\
\text { Oil }\end{array}$ & $\begin{array}{l}\text { Soybean } \\
\text { Oil }\end{array}$ & $\begin{array}{l}\text { Canola } \\
\text { Oil }\end{array}$ & $\begin{array}{l}\text { Linseed } \\
\text { Oil }\end{array}$ & $\begin{array}{l}\text { Palm } \\
\text { Oil }\end{array}$ \\
\hline \multirow{2}{*}{ Cholesterol } & 42.10 & $27.61 \pm$ & $31.60 \pm$ & $32.16 \pm$ & $21.49 \pm$ \\
& $\pm 3.57^{\mathrm{a}}$ & $4.56^{\mathrm{bc}}$ & $4.32^{\mathrm{b}}$ & $2.54^{\mathrm{b}}$ & $3.17^{\mathrm{c}}$ \\
\hline
\end{tabular}

Values are mean $\pm S E, n=3$. Different letters indicate significant differences (Duncan's multiple range test, $\mathrm{p}<0.05$ ).

\section{Whole-body cholesterol content}

Crabs fed the FO-based diet had the highest whole-body cholesterol content than all other dietary treatments (Figure 1). The lowest whole-body cholesterol was from crabs fed the PO-based diet, which was significantly lower than those fed the LSO, CO or FO-based diet. There was no significant difference between crabs fed the SBO or PO-diets (Figure 1).

\section{Discussion}

The results of the current study demonstrate that dietary FO can be completely replaced by SBO, LSO, or CO in the diets of $P$. pelagicus without affecting their growth after 35 days. During this time, the majority of crabs molted at least four times to reach the fifth crab stage, with some reaching the sixth juvenile stage, which is approxi- 
mately half way through their development until market size. Since it is known that $P$. pelagicus require LC-PUFA for their survival and growth, ${ }^{19}$ the ability of the crabs to grow well on the various tested vegetable oils may have been due to residual FO from the fishmeal that was included as the dominant protein source (at $500 \mathrm{~g} \mathrm{~kg}$-1) leading to a total n-3 LC-PUFA of 9.88 to $11.30 \%$. Indeed, more recently when dietary LC-PUFA was deficient in the diets of P. pelagicus early juveniles, there was a steep drop in their survival after only three molts along with significantly lower growth compared diets containing LC-PUFA of only $3.7 \% .^{2}$ It has been suggested that the ability of $P$. pelagicus to grow well with only small amounts of LC-PUFA reflects their natural feeding habits on both animal and plant material, but the necessity of LC-PUFA is probably due to an inability to synthesize these fatty acids from linoleic $(18: 2 n-6)$ and $\alpha$-linolenic $(18: 3 n-3) .^{2}$ In contrast, when $S$. serrata were fed sunflower or SBO as the sole lipids, growth was significantly lower of over two-fold despite residual FO from fishmeal (as the dominant protein source) as well as oils from squid, shrimp and clam meal leading to a total n-3 LC-PUFA of 8.1 and $7.9 \%$, respectively. ${ }^{17}$ This may indicate that $P$. pelagicus have a lower n-3 LC-PUFA requirement than $S$. serrata.

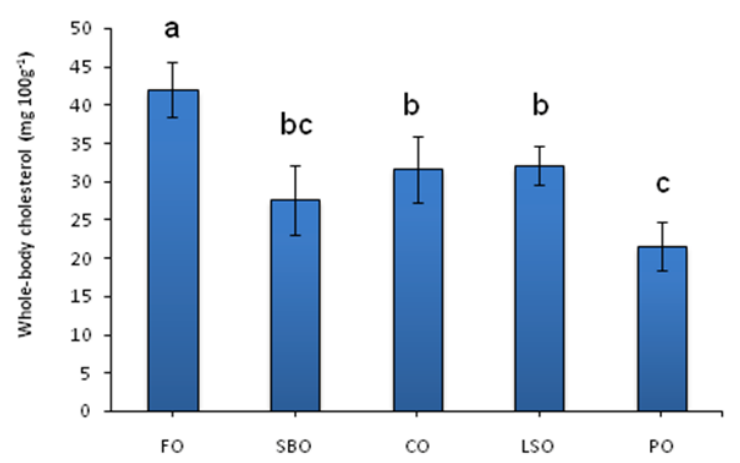

Figure I Whole-body cholesterol content ( $\mathrm{mg} \mathrm{I00} \mathrm{g-I)} \mathrm{of} \mathrm{the} \mathrm{blue} \mathrm{swimmer}$ crab Portunus pelagicus juveniles after 35 days of being fed diets with different lipids. Values are mean $\pm S E, n=3$. Different letters indicate significant differences (Duncan's multiple range test, $\mathrm{p}<0.05$ ). $\mathrm{FO}=$ fish oil; $\mathrm{SBO}=$ soybean oil; $\mathrm{CO}=$ canola oil $\mathrm{LSO}=$ linseed oil $\mathrm{PO}=$ palm oil .

On the other hand, despite the presence of n-3 LC-PUFA in the PO-based diets, at similar amounts to the other vegetable oil based diets, this diet led to significantly lower growth of the crabs compared to those in the other treatments. This may have been due to the high amount of saturated fatty acids (SFA) in the PO diet compared to the other tested diets. This finding is in agreement with a study on $M$. rosenbergii since among various vegetable oils, that included CO, LSO, sunflower seed oil or crude palm oil (CPO), prawns fed the CPO-based diet had the lowest growth performance. ${ }^{18}$ Kim et al. ${ }^{18}$ suggested that since SFA were poorly digested by P. monodon ${ }^{27,28}$ this might have applied to $M$. rosenbergii thus leading to lower growth.

Based on the lower survival and growth of P. pelagicus fed the PO-based diet, this also appears to indicate SFA was poorly digested. Moreover, with the exception of the SBO dietary treatment, crabs fed the PO-based diet had significantly lower whole-body cholesterol content than all the other treatments. A contributor for this likely includes the lower amounts of cholesterol in the vegetable oils compared to FO, although this is unlikely to fully explain such a finding, especially as cholesterol was supplemented at $10 \mathrm{~g} \mathrm{~kg}-1$. Such a supplementation was more than sufficient to satisfy the requirements for $S$. serrate, ${ }^{21}$ which is an essential nutrient for crustaceans due to their inability to synthesize this de novo. ${ }^{29}$ Another possible contributor to the reduced whole-body cholesterol was due the presence of phytosterols, which can diminish cholesterol absorption, ${ }^{30}$ and the tested vegetable oils in the current study are also known to contain this compound. ${ }^{31}$ In addition, it may be possible that cholesterol transport via lipoproteins was disrupted as suggested by Noordin et al. ${ }^{2}$ This certainly requires further research on the influence that different fatty acids could have on cholesterol metabolism in crustaceans. Since cholesterol plays crucial roles such as being a precursor for the molting hormone ecdysone, ${ }^{32}$ this could potentially explain the significantly longer intermolt duration of the crabs fed the SBO and PO-based diets. It was similarly found that $L$. vannamei fed SBO or poultry fat-based diets led to lower cholesterol in the muscle and hepatopancreas, although growth was not significantly impacted after 28 days. ${ }^{16}$

The findings of this study are encouraging since LSO, SBO, or CO can be used to totally replace traditionally used FO as cheaper and more sustainable alternatives in the diets of $P$. pelagicus juveniles without affecting growth. The reduced performance of the crabs fed the PO-based diet may have been due to excessive SFA that reduced fatty acid utilization and/or disrupted cholesterol metabolism. This, however, requires further investigations. Considering PO is an inexpensive lipid source, particularly in Southeast Asia where these crabs are predominately farmed, ${ }^{1,4}$ investigations into the use of PO blends with other plant oils may help further improve cost-effectiveness without compromising productivity. Such research, along with the findings of this study, should assist in more cost-effective and eco-friendly feed formulations of portunid crabs.

\section{Acknowledgements}

This study was funded by a grant from Universiti Putra Malaysia (UPM); project no. GP-IPB/2014/9440403.

\section{Conflicts of interest}

None.

\section{References}

1. Turchini GM, Torstensen BE, Wing Keong Ng. Fish oil replacement in finfish nutrition. Rev Aquacult. 2009;1(1):10-57.

2. Noordin NM, Zeng C, Southgate PC, et al. Effects of dietary fish oil to soybean oil ratio on survival, development, and growth of early juveniles of the blue swimmer crab Portunuspelagicus. J Shellfish Res. 2015;34(3):1065-1072.

3. FAO (Food and Agriculture Organization). FISHSTAT plus: Universal Software for Fisheryv Statistical Time Series, Version 2.3. FAO Fisheries Department, Fishery Information, Data and Statistical Unit, Rome. 2015.

4. Shelley C, Lovatelli A. Mud crab aquaculture: A practical manual. Fisheries and Aquaculture Technical Paper. 2011;567:1-78.

5. Zhao J, Wen X, Li S, et al. Effects of dietary lipid levels on growth, feed utilization, body composition and antioxidants of juvenile mud crab Scylla paramamosain (Estampador). Aquaculture. 2015;435(1):200-206.

6. Jin $\mathrm{M}$, Zhou QC, Zhang $\mathrm{W}$, et al. Dietary protein requirements of the juvenile swimming crab, Portunus trituberculatus. Aquaculture. 2013;414-415:303-308.

7. Sukor SA, Taher S, Ehteshamei F, et al. Effects of different organic acids on the survival, growth, and hepatopancreatic histopathology of the blue swimmer crab, Portunus pelagicus. J Shellfish Res. 2016;35(2):555561

8. Sheen SS, Wu SW. The effects of dietary lipid levels on the growth response of juvenile mud crab Scylla serrata. Aquaculture. 1999;175(12):143-153. 
9. Holme MH, Zeng C, Southgate PC. The effects of supplemental dietary cholesterol on growth, development and survival of mud crab, Scylla serrata, megalopa fed semi-purified diets. Aquaculture. 2006;261(4):1328-1334.

10. Glencross BD. Exploring the nutritional demand for essential fatty acids by aquaculture species. Rev Aquacult. 2009;1(2):71-124.

11. Deshimaru O, Kuroki K, Yone Y. The composition and level of dietary lipid appropriate for the growth of prawn. Bull Jap Soc Fish. 1979;45:591-594.

12. Lim C, Ako H, Brown CL, et al. Growth response and fatty acid composition of juvenile Penaeus vannamei fed different sources of dietary lipid. Aquaculture. 1997;151(1-4):143-153.

13. González-Félix M, Gatlin DM, Lawrence AL, et al. Nutritional evaluation of fatty acids for the open thelycum shrimp, Litopenaeus vannamei: II. Effect of dietary $\mathrm{n}-3$ and $\mathrm{n}-6$ polyunsaturated and highly unsaturated fatty acids on juvenile shrimp growth, survival and fatty acid composition. Aquacult Nutr. 2003;9(2):115-122.

14. Glencross BD, Smith DM, Tonks L, et al. The effect of dietary n-3 and $\mathrm{n}-6$ fatty acid balance on the growth of the prawn Penaeus monodon. Aquacult Nutr. 2002;8(1):43-51.

15. Deering MJ, Fielder DR, Hewitt DR. Growth and fatty acid composition of juvenile leader prawns, Penaeus monodon, fed different lipids. Aquaculture. 1997;151(1-4):131-141.

16. Cheng ZJ, Hardy RW. Protein and lipid sources affect cholesterol concentration of juvenile Pacific white shrimp, Litopenaeus vannamei (Boone). J Animal Sci. 2004;82(4):1136-1145.

17. Unnikrishnan U, Chakraborty K, Paulraj R. Efficacy of various lipid supplements in formulated pellet diets for juvenile Scylla serrata. Aquacult Res. 2010;41(10):1498-1513.

18. Kim YC, Romano N, Lee KS, et al. Effects of replacing dietary fish oil and squid liver oil with vegetable oils on the growth, tissue fatty acid profile and total carotenoids of the giant freshwater prawn, Macrobrachium rosenbergii. Aquacult Res. 2013;44(11):1731-1740.

19. Romano N, Zeng C, Noordin NM, et al. Improving the survival, growth and hemolymph ion maintenance of early juvenile blue swimmer crabs, Portunus pelagicus, at hypo- and hyper-osmotic conditions through dietary long chain PUFA supplementation. Aquaculture. 2012;342-343:24-30.
20. Chen Y, Chen L, Qin JG, et al. Growth and immune response of Chinese mitten crab (Eriocheir sinensis) fed diets containing different lipid sources. Aquacult Res. 2016;47(6):1984-1995.

21. Sheen SS. Dietary cholesterol requirement of juvenile mud crab Scylla serrata. Aquaculture. 2000;189(3-4):277-285.

22. Li X, Wang J, Han T, et al. Effect of dietary phospholipids levels and sources on growth performance, fatty acid composition of the juvenile swimming crab, Portunus trituberculatus. Aquaculture. 2014;430:166172

23. Romano N, Simon W, Ebrahimi M, et al. Dietary sodium citrate improved oxidative stability in red hybrid tilapia (Oreochromis sp.) but reduced growth, health status, intestinal short chain fatty acids and induced liver damage. Aquaculture. 2016;458:170-176.

24. AOAC (Association of Official Analytical Chemists) In: Cunniff PA (Eds.), Official methods of analysis of AOAC International, 16th edition AOAC International, Arlington, Virginia, USA. 1997.

25. Ebrahimi M, Raijon MA, Meng GY, et al. Omega-3 fatty acid enriched chevon (goat meat) lowers plasma cholesterol levels and alters gene expression in rats. BioMed Res Intern. 2014;2014:1-8.

26. Romano N, Zeng Z. The effects of salinity on the survival, growth and haemolymph osmolality of early juvenile blue swimmer crabs, Portunus pelagicus. Aquaculture. 2006;260(1-4):151-162.

27. Merican ZO, Shim KF. Lipid and fatty acid utilization in adult Penaeus monodon fed diets supplemented with various oils. Aquaculture. $1994 ; 123(3-4): 335-347$.

28. Merican ZO, Shim KF. Apparent digestibility of lipid and fatty acids in residual lipids of meals by adult Penaeus monodon. Aquaculture. $1995 ; 133(3-4): 275-286$

29. Teshima S, Kanazawa A, Okamoto H. Absorption of sterols and cholesteryl esters in prawn, P. japonicus. Bull Jap Soc Sci Fish. 1974;40:1015-1019.

30. Gilman CI, Leusch FDL, Breckenridge WC, et al. Effects of a phytosterol mixture on male plasma lipoprotein fractions and testis P450scc activity. Gen Comp Endocrinol. 2003;130(2):172-184.

31. Verleyen T, Forcades M, Verhé R, et al. Analysis of free and esterified sterols in vegetable oils. J Amer Oil Chem Soc. 2002;79(2):117-122.

32. Watson RD, Spaziani E. Uptake of 14C-cholesterol and secretion of ecdysone by crab Y-organs in vitro. Amer Zool. 1982;22:956. 